\title{
Uso de sistemas modulares vegetados para promoção da saúde urbana e atenuação do estresse térmico
}

\author{
Urban health promotion and thermal stress attenuation with the use \\ of green roofs \\ Renato Castiglia Feitosa ${ }^{\mathbf{1}}$
}

DOI: 10.1590/0103-110420195308

RESUMO O processo de urbanização possui efeitos significativos no microclima local, resultando no surgimento das ilhas de calor e comprometimento das condições térmicas no interior de habitações. A aplicação de sistemas modulares vegetados em telhados ou coberturas surge como alternativa à melhoria das condições térmicas no interior de habitações, dispensando, algumas vezes, a climatização artificial e promovendo melhores condições de salubridade no ambiente. A avaliação da atenuação do estresse foi realizada por meio da comparação entre duas habitações protótipos idênticas em que uma possui telhado e paredes vegetadas, e a outra, não. O estresse térmico foi avaliado com base no Índice de Calor, que considera os efeitos combinados da temperatura e umidade relativa. O sistema modular vegetado exerceu papel importante na atenuação do estresse térmico nas habitações, melhorando os parâmetros das condições de salubridade ambiental e minimizando riscos associados à saúde. Os Índices de Calor máximos registrados nos protótipos não vegetado e vegetado foram $57,5^{\circ} \mathrm{C}$ e $49,2^{\circ} \mathrm{C}$ respectivamente. Em termos de atenuação do estresse térmico, a adoção dos sistemas vegetados diminui o tempo de exposição de condições térmicas referentes às condições de 'perigo' a 'perigo extremo' de $17,3 \%$ para $5,4 \%$.

PALAVRAS-CHAVE Áreas verdes. Transtornos de estresse por calor. Saúde da população urbana.

'Fundação Oswaldo Cruz (Fiocruz), Escola Nacional de Saúde Pública Sergio Arouca (Ensp) - Rio de Janeiro (RJ), Brasil renatoensp@gmail.com
ABSTRACT The urbanization process produces significant effects on local microclimate, resulting in heat islands and the worsening of thermal conditions inside housing facilities. The implementation of green roofs arises as an alternative in the improvement of indoor thermal conditions in housings, leading sometimes to energy savings as for air conditioning and promoting better health conditions. The evaluation of thermal stress attenuation was performed by comparing two identical prototype housings, where one has green roof and walls, and the other does not. Thermal stress was evaluated based on the Heat Index, which considers the combined effects of temperature and relative humidity. The green roof system played an important role in the attenuation of thermal stress in housings by improving environmental health conditions and minimizing health related risks. The maximum heat indices recorded in the non-vegetated and vegetated prototypes were $57.5^{\circ} \mathrm{C}$ and $49.2^{\circ} \mathrm{C}$, respectively. In terms of thermal stress attenuation, the adoption of vegetated (green roof) systems decreases the time of exposure of thermal conditions regarding hazardous and extreme danger conditions from $17.3 \%$ to $5.4 \%$.

KEYWORDS Green areas. Heat stress disorder. Urban health. 


\section{Introdução}

O processo de transição de uma sociedade rural para urbana tem como consequências não só as mudanças nos hábitos e estilos de vida das populações, mas também a alteração dos microclimas locais. A mudança na ocupação e no uso do solo altera os fluxos de calor e, consequentemente, a temperatura no meio, contribuindo para uma conjuntura em que o acúmulo de calor é maior que sua dissipação. O resultado é a observância de temperaturas urbanas bem superiores às identificadas em áreas rurais e arborizadas. De acordo com a Agência de Proteção Ambiental Americana ${ }^{1}$, a temperatura anual média dos grandes centros urbanos pode ser de $1^{\circ} \mathrm{C}$ a $3^{\circ} \mathrm{C}$ mais altas do que nas regiões periféricas. A cidade do Rio de janeiro tem experimentado recordes de temperatura durante o verão. No mês de janeiro de 2019 , a temperatura máxima de $40,8^{\circ} \mathrm{C}$ foi registrada em Santa Cruz, na Zona Oeste da cidade ${ }^{2}$. De acordo com a mesma base de dados, temperaturas superiores à $35^{\circ} \mathrm{C}$ tiveram uma frequência de $16,4 \%$.

A elevação crescente de temperatura nos centros urbanos promove impactos diretos e indiretos sobre a saúde. $\mathrm{O}$ calor pode ocasionar mortes em conjunturas especificas de temperatura, umidade, idade da população e etnias. Dados de diferentes regiões do mundo mostram uma associação entre o aumento das temperaturas diárias e o aumento do número de mortes, doenças, e números de hospitalizações ${ }^{3}$. Baseado em estudo realizado durante o verão em Brisbane, Austrália, um aumento de $10^{\circ} \mathrm{C}$ na temperatura foi associado a um aumento de 7,2\% nas internações hospitalares ${ }^{4}$. De acordo com Nicholls et al. ${ }^{5}$, em situações nas quais a temperatura média diária excede $30^{\circ} \mathrm{C}$, há um incremento na taxa de mortalidade de pessoas acima de 65 anos de $15 \%$ a $17 \%$. Índices de mortalidade semelhantes também ocorrem quando as temperaturas mínimas diárias excedem $24^{\circ} \mathrm{C}$. Adicionalmente, são também evidenciados o aumento no número de hospitalizações e a demanda por serviços médicos durante períodos de calor excessivo ${ }^{6,7}$.
Dessa forma, o presente trabalho apresenta uma avaliação comparativa do estresse térmico entre duas edificações protótipo, em que uma delas possui paredes e telhado vegetado, e a outra, não. A avaliação do estresse térmico considerando a ação conjunta da temperatura e umidade relativa é baseada no conceito de 'Temperatura Aparente' ou 'Índice de Calor (IC)'.

Adicionalmente ao impacto sobre a saúde, o aumento considerável da temperatura de regiões urbanas remete à demanda crescente pela geração de energia para climatização de ambientes residenciais e comerciais ${ }^{8-11}$.

A busca por soluções sustentáveis, que objetivam a mitigação de problemas ambientais gerados pelo intenso processo de urbanização, é imprescindível para a melhoria da qualidade de vida nos centros urbanos. A manutenção das áreas verdes e a recomposição das áreas desmatadas contribuem para atenuação dos efeitos das ilhas de calor e para a melhoria das condições térmicas no interior de edificações. Entretanto, em virtude do adensamento habitacional, ações de recomposição vegetal não são significativas devido à carência de áreas disponíveis para tal.

Uma solução que objetiva mitigar tais problemas é a adoção de sistemas modulares vegetados que possam ser aplicados em paredes e telhados de edificações novas e existentes. A aplicação desses sistemas em telhados e coberturas pode ter efeito potencial da atenuação de temperaturas internas em edificações, uma vez que busca aproximar as condições urbanas atuais das condições originais do terreno antes da ocupação humana. Entretanto, em virtude de grande parte das edificações nas grandes cidades serem constituídas por edifícios, é esperado que a aplicação de sistemas vegetados em paredes e fachadas possuam uma contribuição mais significativa na atenuação de ilhas de calor e de temperaturas extremas no interior das edificações. Dessa forma, a combinação de paredes e telhados vegetados promove um melhor desempenho no conforto térmico geral desde pequenas habitações até grandes edifícios. Com esse propósito, o 
presente trabalho objetiva avaliar a atenuação do estresse térmico promovida pela aplicação de sistemas vegetados em uma edificação protótipo quando comparada a uma edificação idêntica totalmente desprovida de vegetação.

\section{Sensação térmica: os impactos combinados da temperatura e umidade na saúde}

A temperatura por si só não constitui fator determinante na sensação térmica experimentada pelos seres humanos. Outros fatores em conjunto com a temperatura, tais como velocidade do ar, fontes radiantes de calor, umidade relativa do ar, tipo de vestimenta, e atividade metabólica, são importantes na avaliação da salubridade ambiental ${ }^{12,13}$. Considerando que a atividade metabólica e o tipo de vestimenta configuram condições particulares individuais, o estresse térmico dependerá das condições ambientais locais. Em habitações desprovidas de sistemas de ventilação forçada e condicionadores de ar, o conforto térmico humano fica sujeito basicamente à ação exclusiva da temperatura e à umidade relativa do ar. No que diz respeito aos riscos de estresse térmico nos seres humanos, os efeitos da temperatura são agravados sob elevados níveis de umidade relativa do ar, uma vez que esta regula as taxas de evaporação do corpo humano pelo suor. Ao evaporar, o suor absorve calor da pele, promovendo o arrefecimento do corpo humano. No caso de elevados níveis de umidade do ar, há diminuição da capacidade de evaporação do suor liberado pela pele, e a sensação de desconforto térmico aumenta. Já o inverso acontece quando os níveis de umidade não são elevados, ocorrendo uma maior capacidade evaporativa, e a consequente melhora na sensação térmica experimentada ${ }^{14}$.

A avalição dos níveis de estresse térmico é baseada em diferentes indicadores. De acordo com Epstein e Moran 12, a quantificação do estresse térmico baseada em um único índice, sob diferentes condições laborais e climáticas, foi objeto de numerosos estudos.

Na quantificação do estresse térmico em função de parâmetros ambientais, foram desenvolvidas metodologias ao longo do último século, tais como Wet Bulb Globe Temperature (WBGT), IC, Humidex, Universal Thermal Climate Index (UTCI), entre outras.

O IC é baseado na pesquisa realizada por Steadman 15-17, que atualmente compõe a base dos sistemas de alerta de calor nos Estados Unidos monitorados pela Administração Oceânica e Atmosférica Nacional (National Oceanic and Atmospheric Administration NOAA -, National Weather Service - NWS). O IC expressa a sensação térmica ou temperatura aparente experimentada pela combinação simultânea de valores de temperatura e umidade relativa do ar. Esse índice pode ser calculado por um algoritmo que fornece a temperatura aparente para determinado par de umidade relativa e temperatura ou por tabelas.

A título de exemplo, considerando a temperatura do ar de $32^{\circ} \mathrm{C}$, são experimentadas temperaturas aparentes equivalentes a $35^{\circ} \mathrm{C}$ e $51^{\circ} \mathrm{C}$ quando a umidade relativa do ar varia de $50 \%$ a $90 \%$ respectivamente. Isso mostra o quanto a umidade do ar pode afetar a termorregulação do corpo humano e comprometer a saúde das populações em situações de temperatura e umidade do ar extremas.

De acordo com o NWS ${ }^{18}$, conforme ilustra o quadro 1 a seguir, o IC é classificado em categorias, baseadas na probabilidade de danos à saúde. 
Quadro 1. Classificação dos IC com base nos possíveis danos ocasionados à saúde

\begin{tabular}{ll}
\hline Índice de calor & Possíveis danos à saúde \\
\hline Abaixo de $27^{\circ} \mathrm{C}$ & Sem risco \\
$27-32^{\circ} \mathrm{C}$ & Cuidado - possibilidade de fadiga após exposição e atividade prolongada \\
$32,1-41^{\circ} \mathrm{C}$ & Cuidado extremo - hipertermia e câimbras de calor possíveis \\
$41,1-54^{\circ} \mathrm{C}$ & Perigo - hipertemia e câimbras de calor prováveis \\
Acima de $54^{\circ} \mathrm{C}$ & Perigo extremo - hipertermia e câimbras de calor iminentes \\
\hline Fonte: Elaboração própria. &
\end{tabular}

A combinação de temperaturas e umidades relativas elevadas são comuns em boa parte do território brasileiro, e compreendem condições adversas em termos de estresse térmico. Desse modo, os riscos relacionados com o estresse térmico devem se basear no IC, e não apenas na temperatura.

Sistemas de alerta baseado em previsões climatológicas, que configuram futuros cenários de risco de estresse térmico, devem ter sua implantação avaliada municipalmente no sentido precaver principalmente a população idosa em tais conjunturas, aconselhando minimizar a exposição ao calor.

\section{O papel da vegetação na atenuação das temperaturas urbanas}

A arborização de ambientes urbanos, além do potencial de atenuação de temperaturas, possui também potencial na umidificação ${ }^{19,20}$. De acordo com Nicodemo e Primavesi21, havendo água disponível no solo, a capacidade de transpiração das plantas é proporcional à área foliar. Desse modo, pode-se afirmar que cada metro quadrado de área vegetada, em função do tipo de espécie escolhida, seria substancialmente eficiente na umidificação e na atenuação de temperatura do ar. Com base em Heisler ${ }^{19}$ e Primavesi et al. ${ }^{\mathbf{2 2}}$, é estimado que a superfície evapotranspirante de uma cobertura vegetal seja de quatro a dez vezes superior à mesma superfície coberta por água.

De acordo com Lanza e Stone ${ }^{23}$, o plantio de árvores é uma estratégia altamente eficaz para resfriar os ambientes urbanos. Lee et al. ${ }^{24}$ também evidenciaram o papel de árvores e superfícies vegetadas na mitigação do estresse térmico em um distrito residencial de Freiburg, sudoeste da Alemanha. Roy et al. ${ }^{25}$ apresentaram uma compilação de artigos, em que são destacadas 25 contribuições que atestam o papel das árvores na atenuação de temperaturas no meio urbano. A vegetação possui efeito na atenuação de temperaturas da superfície terrestre durante o dia e do ar durante a noite 26 .

Tais diferenças nos níveis de temperatura são justificadas pelas diferenças existentes na ocupação e uso do solo. De acordo com Heisler ${ }^{19}$, além impedir a absorção de radiação solar sobre o solo evitando seu aquecimento, grande parte da energia solar interceptada pela vegetação é utilizada em seu processo metabólico e na sua transpiração. Considerando que o calor irradiado por uma superfície aquecida é proporcional à sua temperatura, o sombreamento das superfícies promovido pelas plantas impede essa irradiação. Em superfícies descobertas onde a absorção de radiação solar é direta, o calor absorvido é irradiado, aquecendo o ar em seu entorno e aumentando substancialmente a temperatura do meio urbano. $\mathrm{O}$ desconforto térmico e as condições adversas à saúde humana são substanciais devido à ação direta; e indireta radiada pelo solo e demais superfícies expostas à ação da radiação solar.

Em regiões urbanas, são observadas temperaturas noturnas significativamente superiores às temperaturas de áreas rurais, 
devido ao efeito do calor irradiado pelas superfícies, tais como telhados, fachadas, pavimentos etc., aumentando os efeitos das ilhas de calor e a demanda crescente para geração de energia para climatização de ambientes'. Adicionalmente, as edificações de grande altura aumentam consideravelmente a área de exposição lateral à ação da radiação solar por se tratarem, na grande maioria das vezes, de estruturas cujas áreas laterais, por vezes expostas ao percurso solar, são relativamente superiores às suas dimensões em planta. Nessa condição, em conjunto com os telhados verdes, o uso de paredes e fachadas vegetadas possui efeito considerável na atenuação da temperatura interna das habitações e na redução de gastos de energia com aquecimento ou resfriamento ${ }^{27-31}$.

\section{Métodos}

O papel da vegetação na atenuação do estresse térmico foi avaliado com base na comparação entre duas edificações protótipos idênticas, em que uma delas possui o telhado e as paredes vegetadas, e a outra, não, durante um período de aproximadamente 130 dias $\left(1^{\circ}\right.$ de outubro de 2016 a 8 de fevereiro de 2017). Tais edificações foram construídas em blocos de concreto e possuem as dimensões aproximadas de $1,2 \mathrm{~m} \times 1,5 \mathrm{~m}$ em planta e $1,15 \mathrm{~m}$ de altura. De modo a proporcionar condições idênticas de radiação solar, o aparato experimental foi montado na cobertura do prédio do Centro de Estudos da Saúde do Trabalhador e Ecologia Humana (CESTH), da Fundação Oswaldo Cruz (Fiocruz) localizada no bairro de Manguinhos, Rio de janeiro.

O IC utilizado pelo Serviço Nacional de Meteorologia dos Estados Unidos (NWS) foi empregado no presente estudo na avaliação da melhoria do estresse térmico por meio do uso de sistemas vegetados em habitações protótipos.

O fluxograma na figura 1 seguinte apresenta a metodologia de cálculo do IC17 em função da Temperatura (T) e Umidade Relativa (UR). As temperaturas são calculadas em graus Fahrenheit e depois convertidas para graus Celsius.

Figura 1. Processo de cálculo do Índice de Calor (IC), com base na metodologia proposta pela Serviço Nacional de Meteorologia dos Estados Unidos (NWS)

$$
I C^{\star}=1,1 \times T-10,3+0,047 \times \text { UR }
$$
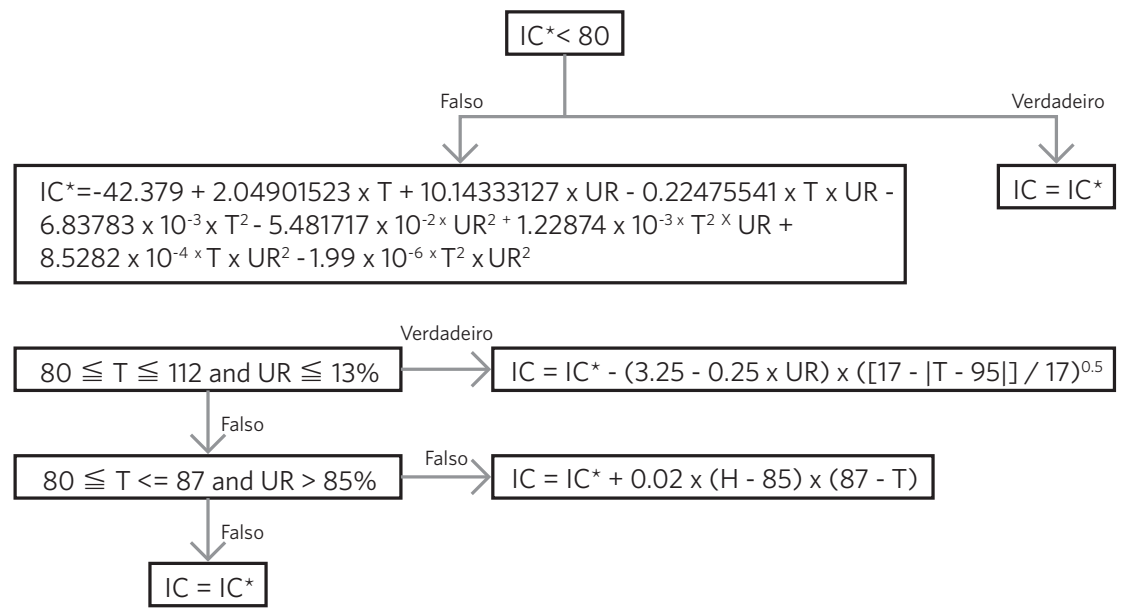

Fonte: Elaboração própria. 
Os dados de umidade relativa e temperatura foram obtidos, simultaneamente, a cada 30 minutos no interior dos protótipos vegetado e não vegetado, utilizando medidores comerciais da marca Extech modelo RHT10, posicionados a $40 \mathrm{~cm}$ abaixo do telhado. A faixa de variação de umidade relativa e temperatura desses medidores correspondem, respectivamente, a $0 \%$ a $100 \%$ e $-40^{\circ} \mathrm{C}$ a $70^{\circ} \mathrm{C}$.

No sentido de oferecer uma alternativa à aplicação de vegetação em larga escala em edificações, optou-se por um sistema modular vegetado que pode ser aplicado tanto em telhados e coberturas quanto em paredes e fachadas. Tal metodologia é constituída por módulos vegetados com aproximadamente $5 \mathrm{~cm}$ de espessura, cuja aplicação pode ser viabilizada praticamente em qualquer estrutura existente devido à baixa sobrecarga do sistema ( $\sim 80 \mathrm{kgf} /$ $\mathrm{m}^{2}$ ). Os sistemas modulares foram aplicados na cobertura e nas paredes da habitação protótipo somente após o total desenvolvimento da vegetação. Pelo fato de o sistema apresentar característica modular removível, a eventual adubação, manutenção e replantio de vegetação constituem processos simples que podem ser realizados fora do local da instalação, minimizando os riscos de operação e facilitando os procedimentos de manutenção.

A aplicação do sistema vegetado no telhado da edificação protótipo obedeceu a seguinte ordenação: preparo da caixa; colocação do tecido geotêxtil; disposição do solo e plantio da vegetação. Para que não ocorresse a perda de solo pelo sistema de drenagem, composto por pequenos orifícios na base do módulo vegetado, ela foi forrada com tecido geotêxtil, que permitiu a drenagem da água, mas impediu a passagem das partículas constituintes do solo.

O sistema modular aplicado nas paredes da edificação protótipo foi constituído por caixas com tampas que possuem seis aberturas nas quais a vegetação é plantada. O solo é previamente colocado nas caixas, e antes da colocação das tampas, é coberto com tecido geotêxtil que funciona como contenção do solo, quando os módulos são dispostos na vertical, em guias ' $U$ ' previamente fixadas nas paredes.

A figura 2 a seguir ilustra o esquema de montagem do sistema cuja drenagem ocorre pelo bordo inferior das caixas.

Figura 2. Esquema ilustrativo da aplicação dos sistemas vegetados em paredes e/ou fachadas

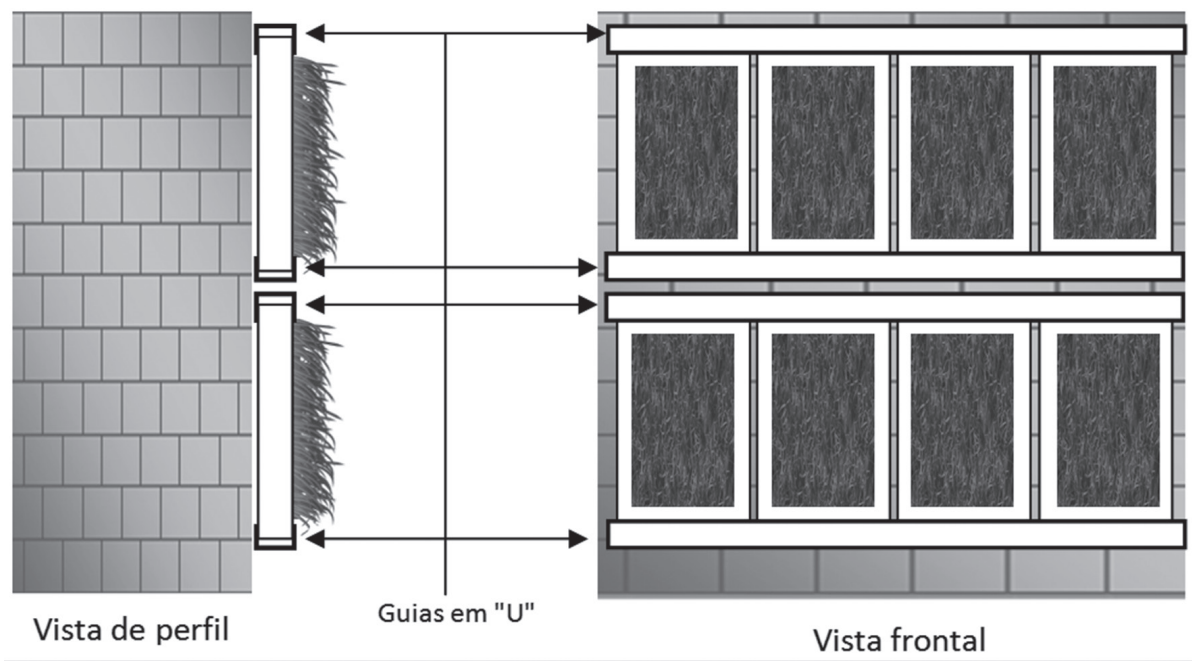


O solo empregado nos módulos vegetados foi constituído por igual proporção de areia e terra adubada de modo a garantir boa capacidade drenante e isolante devido à sua elevada porosidade.

Considerando a impossibilidade da implantação de um sistema de irrigação no local do experimento, plantas do tipo suculentas foram adotadas nos sistemas vegetados devido a sua tolerância à seca e resistência às temperaturas elevadas. Sua composição não favorece seu ressecamento em períodos de estiagem, portanto, suas chances de pegar fogo são remotas. A utilização de tais espécies não é algo obrigatório, mas apenas sugestivo. A única restrição a ser destacada é com relação ao tamanho da vegetação a ser empregada. Devido à pequena espessura de solo adotada que confere baixo peso aplicado na estrutura, apenas vegetações de pequeno porte podem ser empregadas.

\section{Resultados e discussões}

A figura 3 apresenta uma comparação entre temperatura, umidade relativa e IC calculado de acordo com NWS ${ }^{17}$ durante 130 dias. As linhas inferiores nos gráficos representam as diferenças simultâneas de umidade relativa, temperatura, e IC entre os protótipos não vegetado e vegetado.

Trabalhos semelhantes e complementares ao aqui apresentado foram anteriormente publicados por Wilkinson e Castiglia Feitosa ${ }^{32} \mathrm{e}$ Castiglia Feitosa e Wilkinson ${ }^{33}$.

Figura 3. Comparação entre registros de umidade relativa, temperatura e IC observado nos protótipos não vegetado e no protótipo vegetado

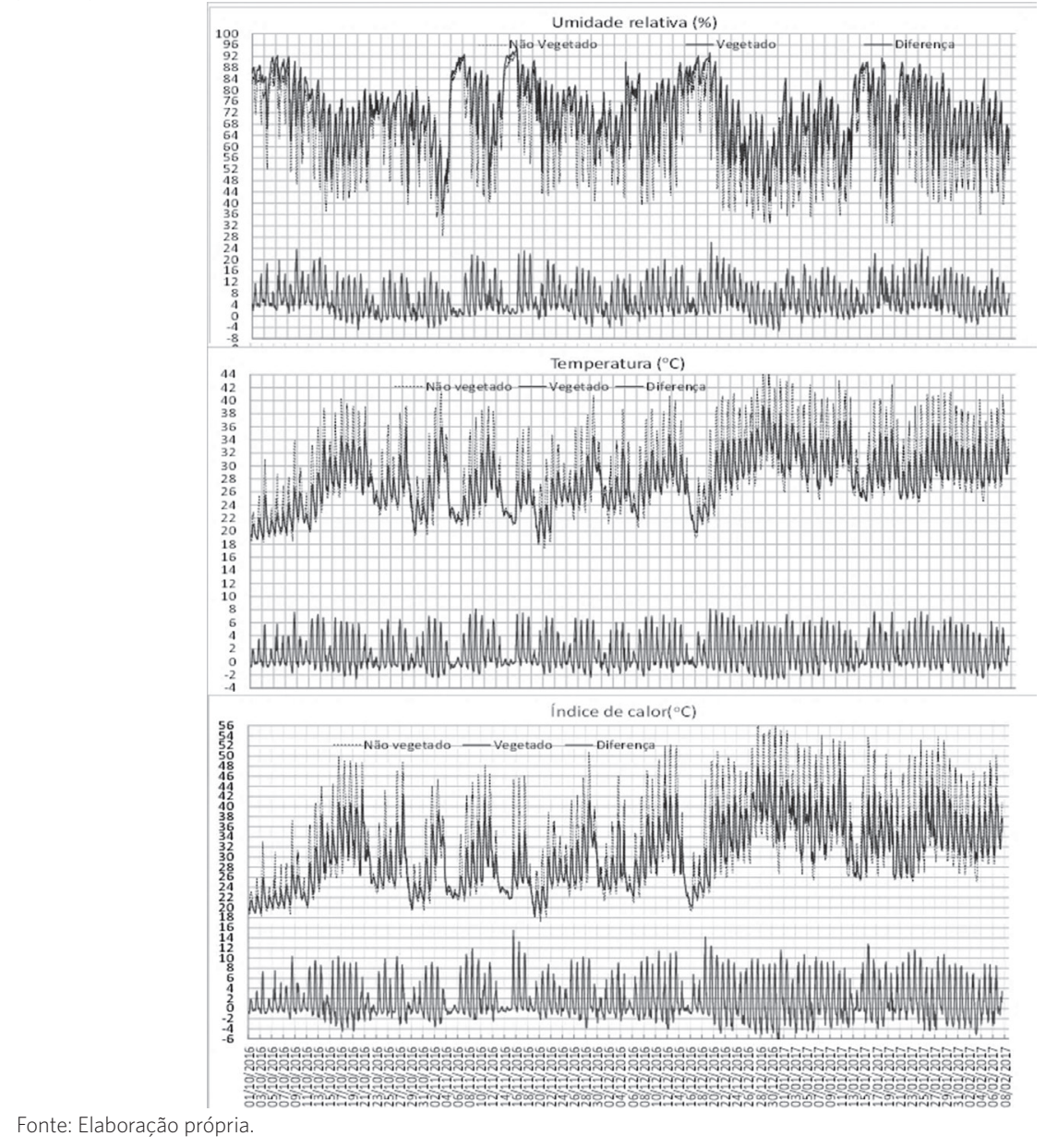


Algumas observações importantes podem ser tecidas com base nos resultados apresentados. As temperaturas máximas observadas nos protótipos não vegetado e vegetado foram, respectivamente: $45,3^{\circ} \mathrm{C}$ e $39,2^{\circ} \mathrm{C}$. A diferença entre a temperatura verificada no interior do protótipo vegetado é consideravelmente inferior à do protótipo não vegetado. Nesse caso, são observadas diferenças simultâneas que variam entre $8,1^{\circ} \mathrm{C} \mathrm{e}-2,7^{\circ} \mathrm{C}$. As diferenças positivas indicam temperaturas superiores na casa não vegetada, que ocorrem no período diurno (entre 12 horas e 15 horas), enquanto as negativas, indicam o contrário e costumam ocorrer nas primeiras horas do dia (entre 1 hora e 6 horas). Tal fato indica que vegetação, além de atenuar os picos de temperatura, é também capaz de retardar a perda e o ganho de calor.

A umidade relativa varia em função da temperatura. Caso a quantidade de água presente no ar atmosférico permaneça em níveis constantes, a umidade relativa variará de uma maneira inversamente proporcional à temperatura. Isto é, a máxima umidade relativa ocorrerá nos períodos de menor temperatura e vice-versa. Entretanto, pode-se observar que a umidade relativa no interior do protótipo vegetado é maior praticamente todo o tempo, inclusive nos instantes em que a temperatura no protótipo vegetado é ligeiramente superior à do não vegetado. Tal fato indica que o protótipo vegetado é mais úmido devido ao aporte de umidade para seu interior em virtude do processo de evapotranspiração das plantas ao seu entorno.

Os registros dos IC no interior da estrutura não vegetada e vegetada corroboraram o papel significativo da vegetação na atenuação do estresse térmico. As médias das edificações protótipos não vegetadas e vegetadas foram, respectivamente, $32,1^{\circ} \mathrm{C}$ e $30,6^{\circ} \mathrm{C}$, enquanto os maiores níveis de IC foram $57,5^{\circ} \mathrm{C}$ e $49,2^{\circ} \mathrm{C}$ As diferenças observadas entre esses índices no interior dos protótipos não vegetado e vegetado variam de $15,5^{\circ} \mathrm{C}$ a $-7,6^{\circ} \mathrm{C}$. As maiores diferenças positivas ocorreram entre as 13 horas e as 16 horas, ao passo que as maiores diferenças negativas foram registradas durante a noite e o início da manhã.

Os 130 dias de avaliação do estresse térmico baseado no IC foram compilados na forma de histograma, por meio de uma análise comparativa da frequência observada nos protótipos vegetado e não vegetado (gráfico 1). As frequências relativas foram classificadas de acordo com as faixas de IC apresentadas no quadro 1, que correlaciona os níveis desse índice e os riscos associados à saúde.

De forma comparativa, com base no gráfico 1, a frequência relativa de condições representativas de condições térmicas extremas, compreendendo IC superiores a $41^{\circ} \mathrm{C}$, apresentou um percentual de ocorrências de $17,3 \%$ e $5,4 \%$, respectivamente, nos protótipos não vegetado e vegetado. Tal condição é categorizada de acordo com NWS18 (quadro 1) como 'perigo' e 'perigo extremo'. Em outras palavras, com base nos percentuais supracitados, pode-se afirmar que as condições extremas de calor no protótipo vegetado representam $31 \%$ das mesmas condições observadas no protótipo não vegetado. 
Gráfico 1. Histograma comparativo do percentual de ocorrências dos IC para os protótipos vegetados e não vegetados

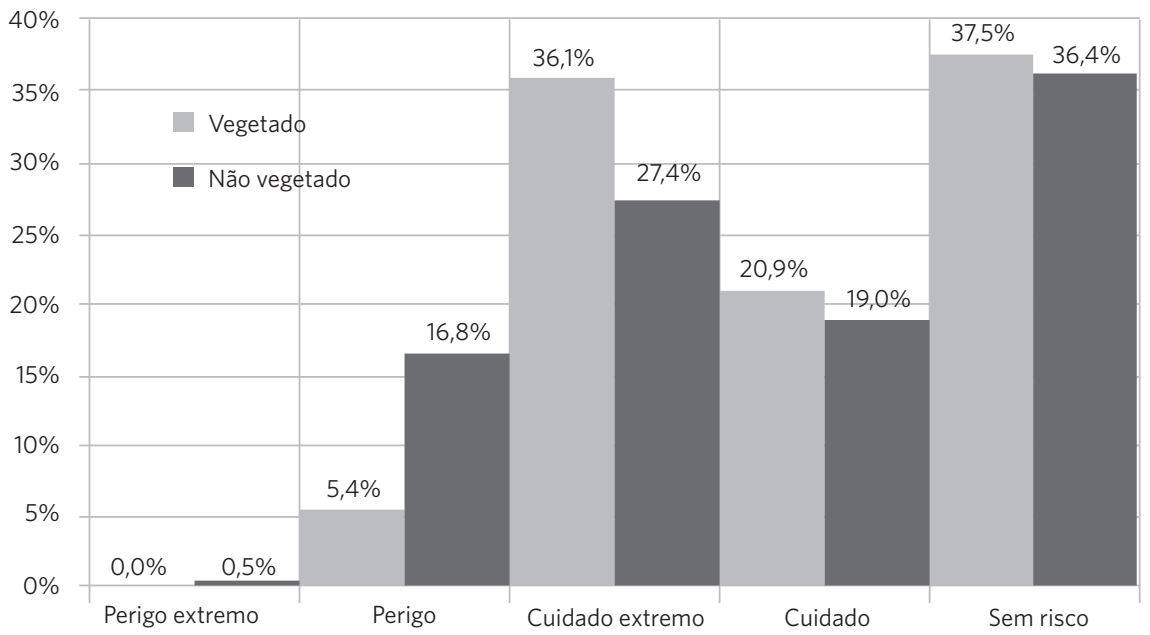

Fonte: Elaboração própria.

Considerando o período experimental de 130 dias e com base nos percentuais apresentados no histograma, pode-se inferir que as condições extremas (IC superior a $41^{\circ} \mathrm{C}$ ) se deram por período equivalente a 22,5 dias no interior do protótipo não vegetado. A adoção de um sistema vegetado em um protótipo comparativo fez com que esse período fosse reduzido para apenas 7 dias, justificando o grande potencial na utilização dos sistemas vegetados na promoção da saúde.

\section{Conclusões}

A atenuação observada na temperatura interna na edificação protótipo vegetada foi significativamente inferior à do protótipo não vegetado. Os níveis de umidade relativa no interior do protótipo vegetado se mostraram superiores aos observados no protótipo não vegetado praticamente ao longo de todo período experimental, indicando um fluxo de umidade para o interior do protótipo vegetado devido ao processo de transpiração das plantas.

O IC é função da combinação dos níveis de temperatura e umidade relativa na promoção do conforto térmico. Desse modo, um fluxo de umidade em virtude da transpiração das plantas para o interior do protótipo vegetado pode compensar as atenuações de temperatura promovidas pela própria vegetação, aumentando os valores dos IC. Isso ocorre uma vez que umidades relativas elevadas diminuem as taxas de evaporação de suor do corpo humano que auxilia na remoção do calor da pele, aumentando a sensação térmica experimentada.

É importante destacar que o fluxo de umidade observado para o interior dos protótipos em virtude da utilização de sistemas vegetados pode estar atribuído a particularidades experimentais, tais como a porosidade dos blocos de concreto que compõem as paredes das habitações.

A aplicação de vegetação nas paredes e nos telhados mostrou significativa contribuição na promoção do conforto térmico e nas condições de salubridade em habitações, mas também de modo indireto pode ter impacto relevante na economia de energia utilizada na climatização de ambientes.

É importante levar em consideração também a aplicação dos sistemas vegetados 
*Orcid (Open Researcher and Contributor ID). nas paredes, visto que no caso de edifícios a cobertura vegetada promove melhoria no conforto térmico apenas no andar subjacente. Desse modo, é esperado que os sistemas vegetados aplicados em paredes e fachadas tenham uma contribuição mais significativa devido à maior área lateral de exposição à radiação solar.

Os sistemas vegetados possuem um papel relevante na atenuação do estresse térmico em edificações. A adoção de sistemas vegetados pode também colaborar para a absorção de gás

\section{Referências}

1. EPA United States Environmental Protection Agency. Heat Island Effect [internet]. [acesso em 2019 maio 25]. Disponível em: http://www.epa.gov/heatisland/ index.htm.

2. Fundação GEO-RIO. Sistema Alerta Rio [internet]. [acesso em 2019 ago19]. Disponível em: http://alertario.rio.rj.gov.br/.

3. Vutcovici M, Goldberg MS, Valois MF. Effects of diurnal variations in temperature on non-accidental mortality among the elderly population of Montreal, Quebec, 1984 - 2007. Int J Biometeorol. 2014; 58(5):843-852.

4. Hondula DM, Barnett AG. Heat-related morbidity in Brisbane, Australia: spatial variation and area-level predictors. Environ. health perspect. 2014; 122(8):831836.

5. Nicholls NL, Skinner C, Loughnan M, et al. A sim- carbônico e poluentes atmosféricos. As plantas empregadas possuem, durante o processo fotossintético, capacidade de retenção de carbono atmosférico, podendo contribuir também para o combate ao aquecimento global.

\section{Colaborador}

Feitosa RC (0000-0003-0724-1993)* é responsável pela elaboração do manuscrito. *Orcid (Open Researcher and Contributor ID). ple heat alert system for Melbourne, Australia. Int. J. Biometeorol. 2008; 52(5):375-384.

6. Anderson GB, Bell ML, Peng RD. Methods to calculate the heat index as an exposure metric in environmental health research. Environ. health perspect. 2013; 121(10):1111-1119.

7. Gronlund CJ, Zanobetti A, Schwartz JD, et al. Heat, heat waves, and hospital admissions among the elderly in the United States, 1992 - 2006. Environ. health perspect. 2014; 122(11):1187-1192.

8. Kolokotroni M, Ren X, Davies M, et al. London's urban heat island: impact on current and future energy consumption in office buildings Energ buildings. 2012; 47(4):302-311.

9. Santamouris M, Papanikolaou N, Livada I, et al. On the impact of urban climate to the energy consumption of buildings. J. Sol. 2001; 70(3):201-216. 
10. Santamouris M, Cartalis C, Synnefa A, et al. On the impact of urban heat island and global warming on the power demand and electricity consumption of buildings - a review, Energ buildings. 2015; 98(1):119124.

11. Susca T. Green roofs to reduce building energy use? A review on key structural factors of green roofs and their effects on urban climate. Build. environ. 2019; 162(9):106273.

12. Epstein Y, Moran DS. Thermal Comfort and the Heat Stress Indices, Ind Health. 2006; 44(3):388-98.

13. Chindapol S, Blair J, Osmond P, et al. A suitable thermal stress index for the elderly in summer tropical climates. Procedia Eng. 2017; 180(10):932-943.

14. Lamberts R, Dutra L, Pereira FOR. Eficiência Energética na Arquitetura [internet]. 3. ed. São Paulo: Procel/ProLivros; 2014. [acesso em 2019 ago 15]. Disponível em: http://www.labeee.ufsc.br/sites/default/ files/apostilas/eficiencia_energetica_na_arquitetura.pdf.

15. Steadman RG. The assessment of sultriness. Part I: A temperature-humidity index based on human physiology and clothing science. J Appl Meteorol. 1979a; 18(4):861-873.

16. Steadman RG. The assessment of sultriness. Part II: Effects of wind, extra radiation and barometric pressure on apparent temperature. J Appl Meteorol. 1979b; 18(4):874-885.

17. Steadman RG. A universal scale of apparent temperature. J. Appl. Meteor. Climatol. 1984; 23(8):16741687.

18. National Weather Service. National Oceanic and Atmospheric Administration Heat Index Chart [internet]. [acesso em 2019 maio 26]. Disponível em: https://www.weather.gov/ffc/hichart.

19. Heisler GM. Trees and human comfort in urban areas. J. for. 1974; 72(8):466-469.
20. McPherson G, Nowak D, Heisler G, et al. Quantifying urban forest structure, function, and value: the Chicago Urban Forest Climate Project. Urban Ecosystems. 1997; 1(3):49-61.

21. Nicodemo LF, Primavesi O. Por que manter árvores na área urbana? [internet]. São Carlos: Embrapa Pecuária Sudeste; 2009. [acesso em 2019 jul 14]. Disponível em: https://www.infoteca.cnptia.embrapa.br/ bitstream/doc/82803/1/Documentos89.pdf.

22. Primavesi O, Arzabe C, Pedreira MS. Aquecimento global e mudanças climáticas: uma visão tropical integrada das causas, dos impactos e de possíveis soluções para ambientes rurais ou urbanos. [internet]. São Carlos: Embrapa Pecuária Sudeste; 2007. [acesso em 2019 jul 17]. Disponível em: http://queimadas. cptec.inpe.br/ rqueimadas/material3os/2007_Primavesi_etal_Mudancas_EMBRAPA_DE3os.pdf.

23. Lanza K, Stone Jr B. Climate adaptation in cities: What trees are suitable for urban heat management? Landscape urban Plan. 2016; 153(9):74-82.

24. Lee H, Mayer H, Chen L. Contribution of trees and grasslands to the mitigation of human heat stress in a residential district of Freiburg, Southwest Germany, Landscape urban Plan. 2016; 148(4):37-50.

25. Roy S, Byrne J, Pickering C. A systematic quantitative review of urban tree benefits, costs, and assessment methods across cities in different climatic zones. Urban for urban Gree. 2012; 11(4):351-363.

26. Shiflett SA, Liang LL, Cruma SM, et al. Variation in the urban vegetation, surface temperature, air temperature nexus, Sci Total Environ. 2017; 579(1):495505.

27. Alexandria E, Jonesb P. Temperature decreases in an urban canyon due to green walls and green roofs in diverse climates. Build. environ. 2008; 43(4):480-493.

28. Cameron RWF, Taylor JE, Emmett MR. What's 'cool' in the world of green façades? How plant choice influences the cooling properties of green walls. Build. environ. 2014; 73(3):198-207. 
29. Yaghoobian N, SrebricJ. Influence of plant coverage on the total green roof energy balance. Energ buildings. 2015; 103(9):1-13.

30. Vox G, Blanco I, Schettini E. Green façades to control wall surface temperature in buildings, Build. environ. 2018; 129(2):154-166.

31. Malys L, Musy M, Inard C. A hydrothermal model to assess the impact of green walls on urban microclimate and building energy consumption, Build. environ. 2014; 73(3):187-197.
32. Wilkinson SJ, Castiglia Feitosa R. Retrofitting Housing with Lightweight Green Roof Technology in Sydney, Australia, and Rio de Janeiro, Brazil, Sustainability. 2015; 7(1)1081-1098.

33. Feitosa RC, Wilkinson S. Retrofitted green roofs and walls and improvements in thermal comfort. In: Workshops and summer schools; 2017 Jun 12; Sydney. Off-Grid Technology Workshop; 2017. p. 020006-1 - 020006-8.

Recebido em 29/04/2019

Aprovado em 11/10/2019

Conflito de interesses: inexistente

Suporte financeiro: não houve 